\title{
Comparison of the visual texture calculation methods by image analysis, applied to mirror and scaled carp skin
}

\section{Aynalı ve pullu sazan derisine uygulanan görüntü analizi ile görsel tekstür hesaplama yöntemlerinin karşılaştırılması}

\author{
Bahar Gümüş \\ Department of Gastronomy and Culinary Arts, Faculty of Tourism, Akdeniz University, Antalya, 07058, Turkey \\ (D) https://orcid.org/0000-0001-9232-8481 \\ Gümüş, B. (2021). Comparison of the visual texture calculation methods by image analysis, applied to mirror and scaled carp skin. Ege Journal of Fisheries \\ and Aquatic Sciences, 38(3), 383-391. DOI:10.12714/egejfas.38.3.15
}

Abstract: Regions of interest (ROI) representative of the visual texture of images of mirror carp Cyprinus carpio carpio and scaled carp Cyprinus carpio were taken. Red, green, blue and grayscale (R, G, B, GS) histograms of these ROI were calculated. The following methods of visual texture calculations were performed on the ROls: 1) image energy based on histograms, 2) image entropy based on histograms, 3) image energy based on co-occurrence matrices, 4) image entropy based on co-occurrence matrices, 5) texture based on fractal dimensions, 6) texture based on texture primitives method. Calculations were performed for color and grayscale images. The identification of the smoothest and roughest ROls depended on the method used. The largest range between the minimum and maximum values was found in the co-occurrence matrix-based entropy calculation. A close second was the texture change index (TCl) method.

Keywords: Cyprinus carpio, visual texture, histograms, co-occurrence matrices, fractals

Öz: Aynalı sazan (Cyprinus carpio carpio) ve pullu sazan (Cyprinus carpio) görüntülerinin görsel tekstürü temsil eden ilgili bölgeleri (ROI) değerlendirilmiştir. Bu ROl'lerin kırmızı, yeşil, mavi ve gri (R, G, B, GS) histogramları hesaplanmıștı. ROI'lere aşağıdaki görsel doku hesaplama yöntemleri uygulanmıștır: 1) Histogramlara dayalı görüntü enerjisi, 2) Histogramlara dayalı görüntü entropisi, 3) Eşdizimlilik matrislerine dayalı görüntü enerjisi, 4) Eşdizimlilik matrislerine dayalı görüntü entropisi, 5) Fraktal boyutlara dayalı tekstür, 6) Tekstür pirimitif yöntemine dayalı tekstür'dür. Hesaplamalar renkli ve gri tonlamalı resimler için yapıımıștır. En düz ve en kaba ROl'lerin tanımlanmasının kullanılan yönteme bağlı olduğu bulunmuștur. Minimum ve maksimum değerler arasındaki en büyük aralık, entropi hesaplamasına bağlı eşdizimlilik matrisinde tespit edilirken ikinci büyük aralık tekstür değişim indeksi (TCl) yöntemiyle bulunmuştur.

Anahtar kelimeler: Cyprinus carpio, görsel doku, histogramlar, eşdizimlilik matrisleri, fraktallar

\section{INTRODUCTION}

In most agricultural materials, colors are distributed nonuniformly over the surface of the material (Balaban, 2008). Regarding the surface of most fruits (apple, mango, watermelon, ripe banana, etc.), fish, meat, grains, the colors are not uniformly distributed. In the case of e.g., meat, this stems from the difference in color between the muscle fiber and fat and their distribution. In the case of fish, it is the differences in the scales and the colorings that are genetic in nature. In the case of most fruits, it is the distribution of the individual components (carotenoids, anthocyanins, etc). Therefore, the amount / level of colors as well as their distribution is important.

Color, size, shape and visual texture are among the properties that can be obtained by image analysis of foods (Sharma et al., 2001; Zheng et al., 2006). Visual texture is different from the touch / squeeze-based texture; it refers to visual non-uniformity, and uneven patterns of the surface.

An image is composed of pixels containing color or intensity information. A pixel in a color image, generally has red $(R)$, green $(G)$, and blue $(B)$ components. The $R, G$, and $B$ values change from 0 to 255 . Bits per pixels of a grayscale image are different than those of a color image. For a grayscale image, the pixels have values changing from 0 to 255; 0 being black and 255 being white.

Tamura et al. (1978) started the research on the lexicon of visual texture. The images that they describe are grayscale, and not related with food. There are a very limited number of studies on the visual texture of foods. Watermarking in salmon is a good example of visual texture (Oliveira et al, 2006). Balaban et al. (2014) quantified the change in the redness value in the skin of gurnard, as well as its distribution. However, they did not quantify the visual texture. Bharati et al. (2004) used visual texture methods to classify rolled steel sheets into various quality grades. Gray level (Partio et al., 2002) or color analysis (Hendrawan et al., 2019) can be used to develop texture properties of surfaces. Parameters can be developed based on histograms or based on co-occurrence matrices. Histograms are very easy to develop for an image, since they represent the counts of individual $\mathrm{R}$, or $\mathrm{G}$, or $\mathrm{B}$, or grayscale values of every pixel in 
the image. Co-occurrence matrices are slightly more complicated, since they require a direction and a step size for the definition of matrix elements. However, they are also easy to develop.

The objective of this study was to apply image analysis based visual texture calculation methods to regions of interest of carp pictures. The visual texture parameters were measured by 6 different methods, and the sensitivity of the methods were compared.

\section{MATERIALS AND METHODS}

\section{Fish samples and image acquisition}

Images of common carp (mirror and scaled) raised in concrete tanks of Republic of Turkey Ministry of Agriculture and Forestry, Mediterranean Fisheries Research Production and Training Institute, Kepez, Antalya, Turkey were used.

Pictures were taken using a modified light box (120-cm high, 60-cm wide, and 60-cm deep) designed by Luzuriaga et al. (1997) under a Nikon D610 DSLR camera (Nikon Corp., Tokyo, Japan) with a 24-300 mm zoom Nikon lens with a circular polarizing filter that camera settings are given in Table 1. The details of light box and color reference were given in the study carried out by Gümüş et al. (2021).

Table 1. The Nikon D610 camera control settings for front-lighting and back-lighting images.

\begin{tabular}{lll}
\hline Camera settings & Front-lighting & Back-lighting \\
\hline Exposure mode & manual & manual \\
Shutter speed & $1 / 2.5 \mathrm{sec}$ & $1 / 4 \mathrm{sec}$ \\
Aperture & $\mathrm{f} / 9$ & $\mathrm{f} / 9$ \\
Exposure compensation & $0 \mathrm{EV}$ & $0 \mathrm{EV}$ \\
ISO sensitivity & 200 & 200 \\
White balance & Preset 1 & Preset 1 \\
Image small size (pixels) & $3008^{*} 2008$ & $3008^{*} 2008$ \\
\hline
\end{tabular}
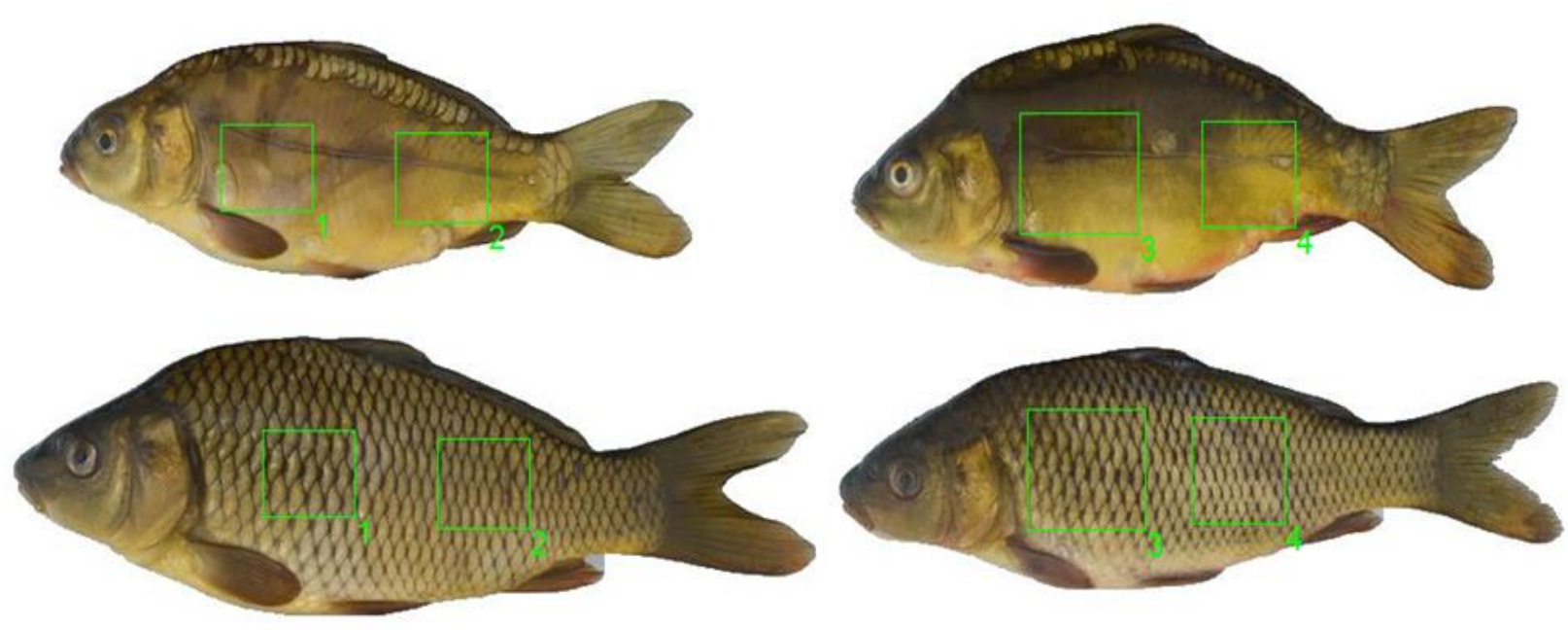

Figure 1. Regions of interest for mirror carp (above), and scaled carp (below)
Pictures were taken with two-image method described by Alçiçek and Balaban (2012). Then, the images using the silhouette (back-lighted) picture were segmented with using the LensEye-NET software (Engineering and Cyber Solutions, Gainesville, FL, USA).

\section{Image analysis}

Corel PhotoPaint (Corel Corp., Ottawa, Ontario, Canada) was used to clear the images taken by camera to isolate the color reference. All visual texture analyses (energies and entropies based on histograms and co-occurrence matrices, fractal dimensions), and texture primitive analyses were performed by using the software LensEye-NET. Two mirror carp images, and two scaled carp images were chosen at random.

In Figure 1, Rectangular Regions of Interest (ROls) are shown. The size and location of the ROls were selected to show representative regions of the fish. ROI 1 was selected to show a lighter area of the mirror carp 1, closer to the head without the interference of the pectoral fin or gills. ROI 2 was selected to show the mid-section area close to the tail, again without interference from the anal fin. ROI 3 shows a similar area in mirror carp 2, similar to mirror carp 1. Since mirror carp 2 has more width, ROI 3 area is larger than ROI 1 area. $\mathrm{ROI} 4$ was selected in mirror carp 2, in an area similar to ROI 2 in mirror carp 1. Again, this area is larger than that of ROI 2. Once the 4 ROls were selected in mirror carp, they were replicated as areas in scaled carp. The only difference is that they were placed close to the midline of the fish to represent the scales without other interference.

For the mirror carp, the surface looks smooth, with little visual texture roughness. For the scaled carp, the scales constitute a fairly ordered visual texture. The ROls close to the head have more distance between the scales compared to the ROI close to the tail. 
Calculation of the energy, entropy, fractals, and texture change index (tci)

Histogram-based energies and entropies: A histogram is the distribution of colors and counts the number of occurrences of $R, G$ and $B$ values for each pixel of the object.
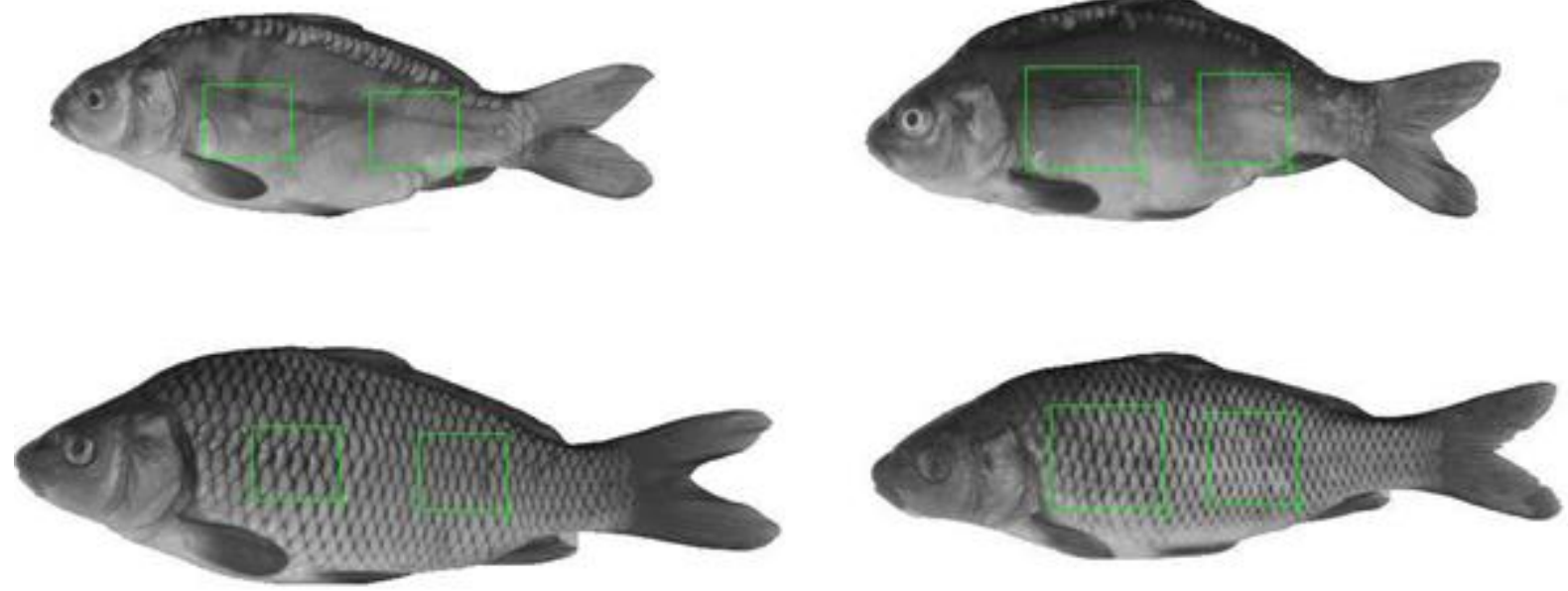
grayscale is (Padmavathi and Thangadurai, 2016):

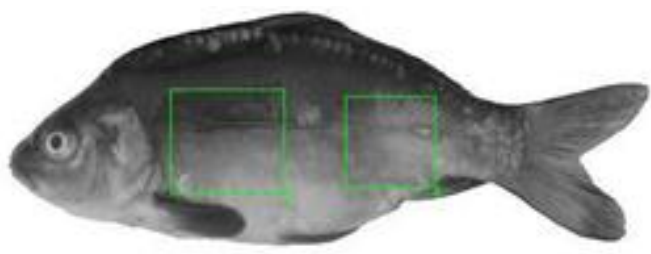

Figure 2. Grayscale images and regions of interest in mirror carp (left), and scaled carp (right) images

Once a histogram is obtained (R, G, B or GS), the energy of an image can be calculated as:

$E=\sum_{k=0}^{M-1}\left(p_{k}\right)^{2}$

$($ Eqn.2)

where $M=256$, and $E$ is the energy of the image, based on $\mathrm{R}, \mathrm{G}, \mathrm{B}$, or $\mathrm{GS}$ histograms.

The entropy of an image is given by the equation (Larkin, 2016):

$H=-\sum_{k=0}^{M-1} p_{k} \log _{2}\left(p_{k}\right)$

(Eqn.3)

Where $M=256$, and $H$ is the entropy of the image, based on the R, G, B, and GS histograms.

Co-occurrence matrix-based energies and entropies: The co-occurrence matrix is a symmetric square matrix, with 256 rows (from 0 to 255), and 256 columns ( 0 to 255). This matrix can be considered as an accumulator, counting the number of times neighboring pixels have certain defined characteristics. In the generation of the matrix requires a direction as 0,45 , 90 and 135 degrees and a step size d measured in pixels (Zucker and Terzopoulos, 1980). The co-occurrence matrix is used as a "statistical" method in the traditional analysis of
A grayscale (GS) (Figure 2) histogram can also be constructed, and its counts gives the number of pixels of the image. The conversion of a pixel with $(R, G, B)$ colors to

Grayscale Value $=0.3{ }^{*} R+0.59{ }^{*} G+0.11{ }^{*} B($ Eqn. 1)

visual texture (Pathak and Barooah, 2013). The energy equation according to Tuceryan (1998) becomes:

$E=\sum_{i} \sum_{j} P_{d}^{2}(i, j)$

(Eqn. 4)

The entropy equation becomes:

$$
H=-\sum_{i} \sum_{j} P_{d}(i, j) \log P_{d}(\mathrm{i}, \mathrm{j}) \quad \text { (Eqn.5) }
$$

Fractal Analysis: Calculation the fractal dimension of an image is used the box counting method. At a given point $p(X$, $Y)$, the sum of all $R, G, B$, and grayscale intensities $(0-255)$ are added, at increasingly larger neighborhoods (Varma and Garg, 2007). Then the log of these sums vs log(d) is plotted. This plot is expected to be a straight line, with a slope and an intercept given in Eqn.5.

The sum of the intensities at a given point $p$, for a given $d$ is used to calculate the local fractal dimension $D(p)$ :

$\log \left[\sum I(p, d)\right]=D(p) \log (d)+L(p)$

(Eqn.6)

where the slope $D(p)$ is the local fractal dimension (also called the Holder exponent), $L(p)$ is the local intercept local $\log$ fractal length, $p$ is a given point, and $d$ is the neighborhood size. 
Texture Primitives and Texture Change Index: Another method to quantify the distribution of colors is the "primitives" method (Zheng et al., 2007; Balaban, 2008). The intensity difference in case of a texture primitive is:

$\Delta I_{t}=\sqrt{\left(R_{i}-R_{j}\right)^{2}+\left(G_{i}-G_{j}\right)^{2}+\left(B_{i}-B_{j}\right)^{2}} \quad($ Eqn. 7)

For a given threshold, the image may display many texture primitives. Intuition tells us that the more primitives, the more textured the image. Texture Change Index (TCl) described by Balaban (2008) was used to calculate texture primitives:

$\mathrm{TCI}=\frac{\text { (Sum of primitive intensity differences)(Number of primitives) }}{\text { (Sum of distances between primitives)(Object area) }}$

The intensity threshold was arbitrarily set to 5 . The $\mathrm{TCl}$ values of color images and grayscale images (Figure 2) were calculated.

\section{RESULTS AND DISCUSSION}

Figures 3, 4, 5 and 6 represent the R, G, B, and GS histograms of the ROls for mirror carp and scaled carp images. It is evident that except for the $3^{\text {rd }} \mathrm{ROI}$ of mirror carp which is darker, the $\mathrm{R}$ histograms are relatively comparable. The same can be said for the $G$ histogram (Figure 4): the 3 rd $\mathrm{ROI}$ is darker, therefore it has relatively lower $G$ values. For the $B$ histogram, the $2^{\text {nd }}, 3^{\text {rd }}$ and $4^{\text {th }}$ ROls of mirror carp stand separate from the rest. In the grayscale histogram (Figure 6) the $3^{\text {rd }} \mathrm{ROI}$ for mirror carp again stands out, since this ROI is darker, it has relatively lower grayscale values.

Table 2 presents the results of histogram-based energy calculations for R, G, B, and GS histograms. Because the histograms are different, there are differences in $R, G, B$, and $\mathrm{GS}$ energies. The individual energy values are very small, in the $10^{-2}$ range. This may be disadvantageous if fine separation of visual texture using histogram-based energy is required.

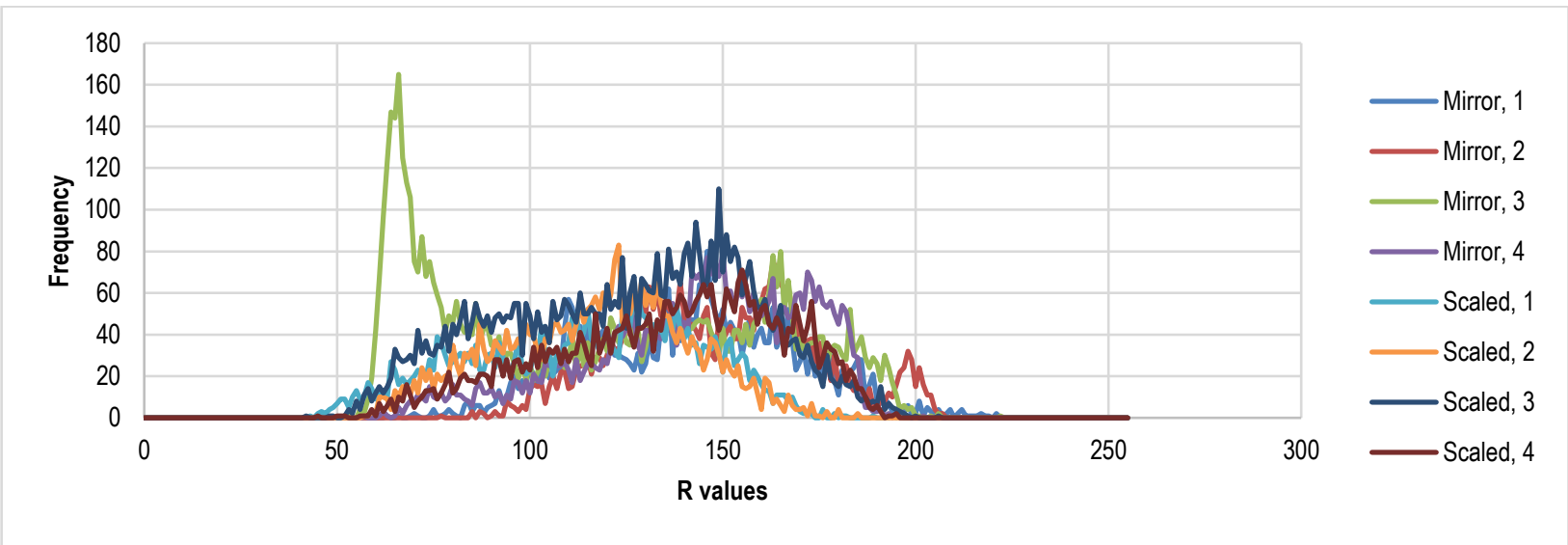

Figure 3. $\mathrm{R}$ histograms of mirror and scaled carp image objects

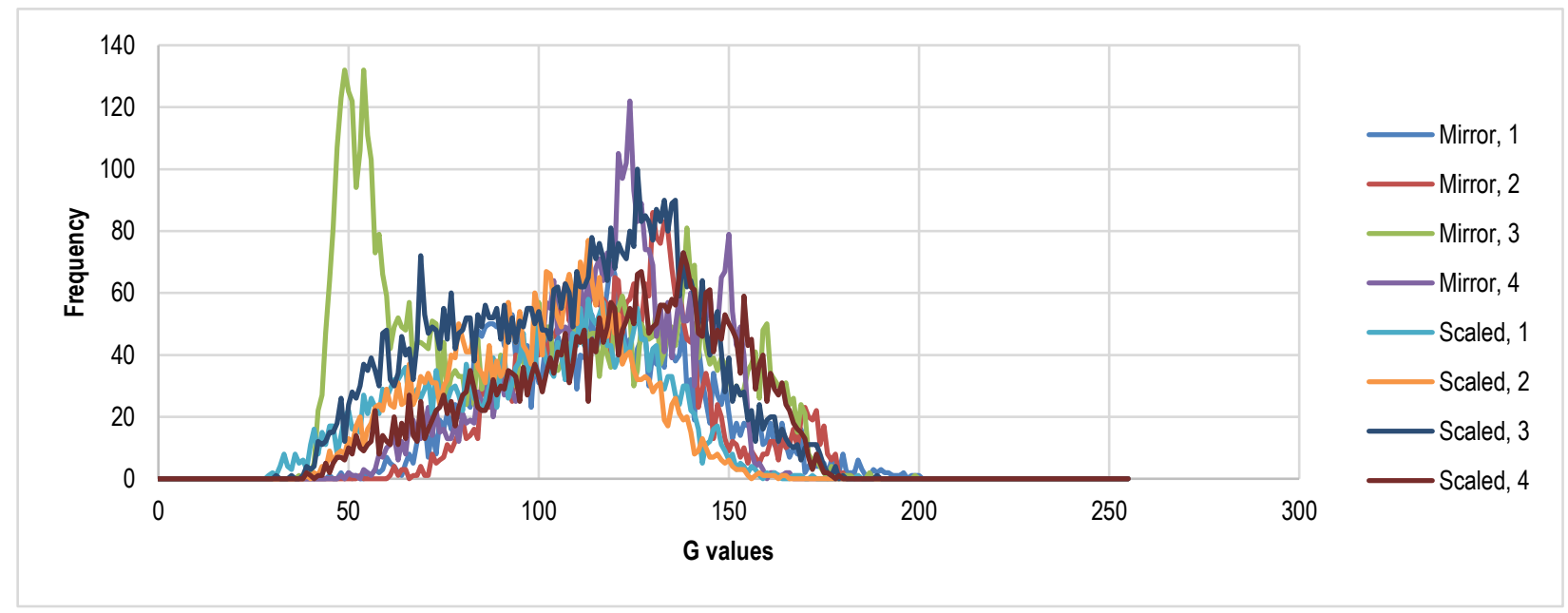

Figure 4. G histograms of mirror and scaled carp image objects 


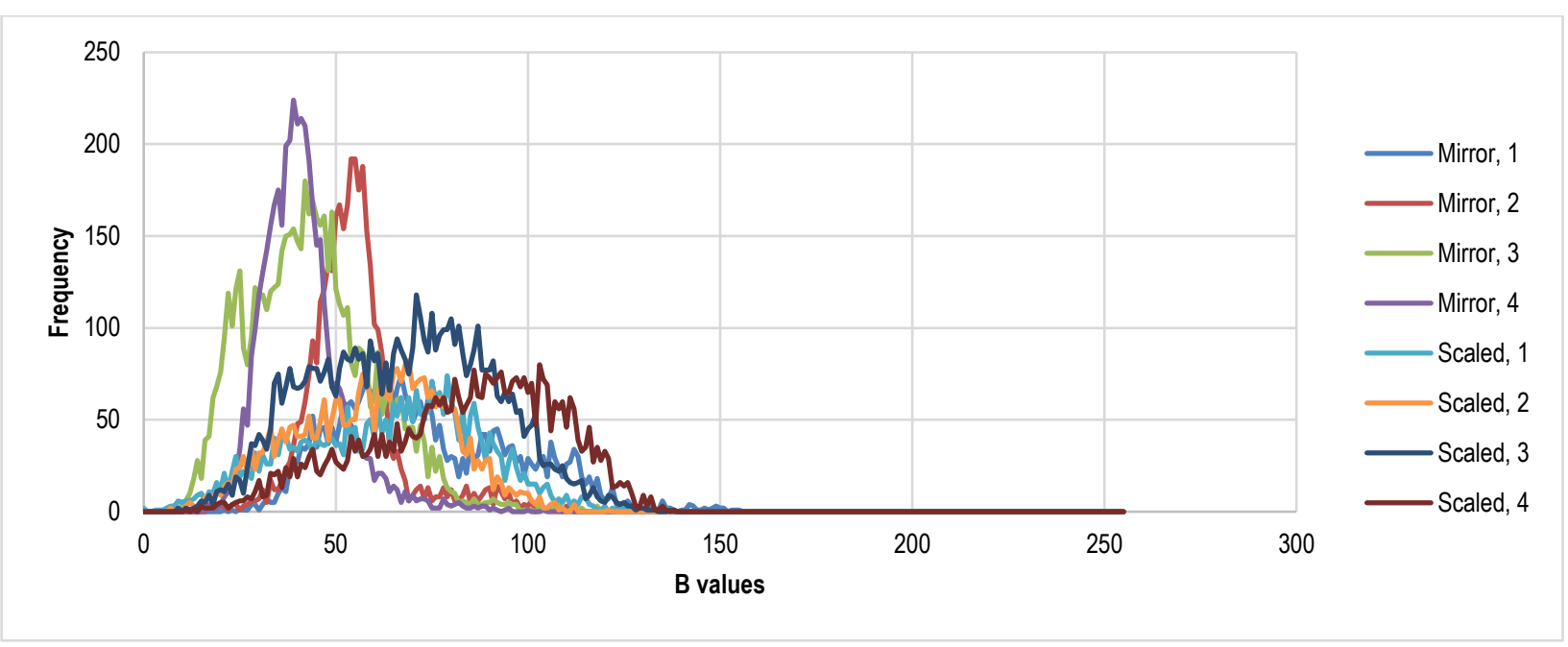

Figure 5. B histograms of mirror and scaled carp image objects

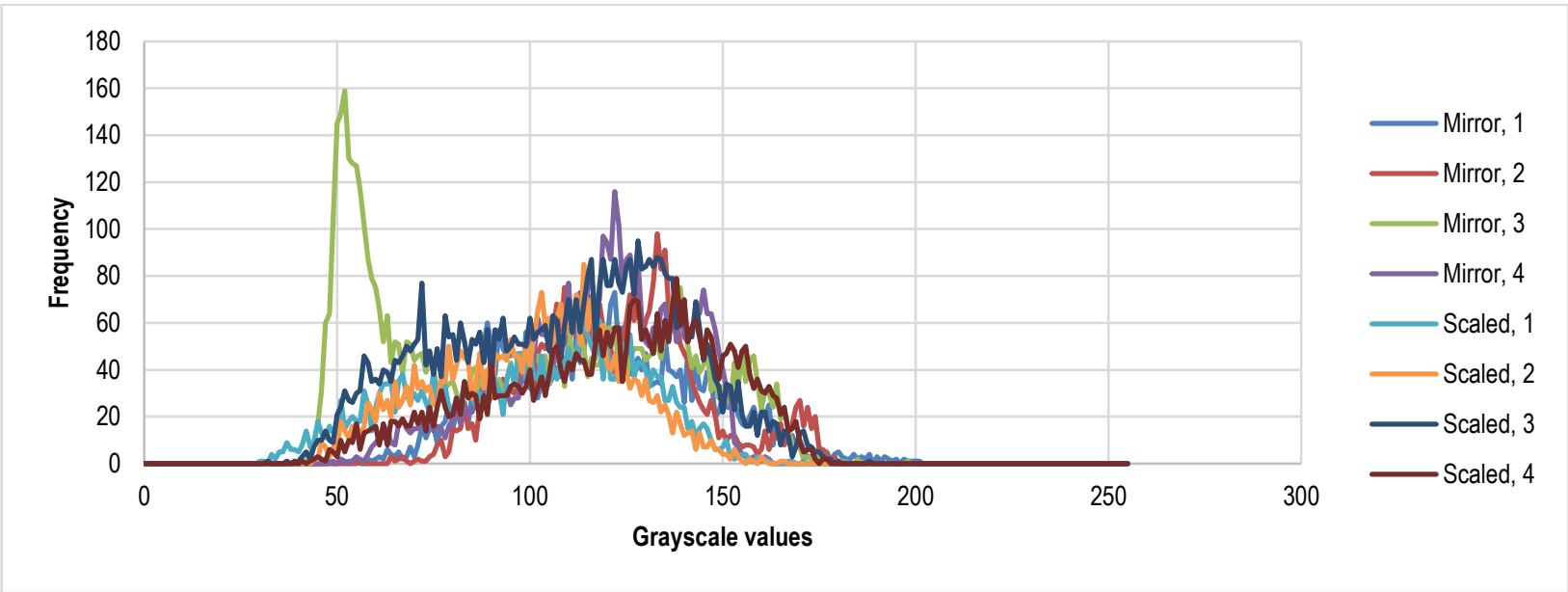

Figure 6. Grayscale histograms of mirror and scaled carp image objects

Table 2. Histogram based energies of carp image objects

\begin{tabular}{|c|c|c|c|c|c|c|c|c|}
\hline \multirow{2}{*}{ Object } & \multicolumn{4}{|c|}{ Mirror carp } & \multicolumn{4}{|c|}{ Scaled Carp } \\
\hline & 1 & 2 & 3 & 4 & 1 & 2 & 3 & 4 \\
\hline R energy & 0.011 & 0.010 & 0.010 & 0.011 & 0.010 & 0.012 & 0.009 & 0.010 \\
\hline G energy & 0.011 & 0.010 & 0.010 & 0.013 & 0.010 & 0.012 & 0.009 & 0.010 \\
\hline B energy & 0.013 & 0.012 & 0.018 & 0.033 & 0.012 & 0.014 & 0.012 & 0.012 \\
\hline Avg. RGB & 0.012 & 0.011 & 0.012 & 0.019 & 0.011 & 0.013 & 0.010 & 0.010 \\
\hline Std RGB & 0.001 & 0.001 & 0.005 & 0.012 & 0.001 & 0.002 & 0.002 & 0.001 \\
\hline GS energy & 0.011 & 0.010 & 0.010 & 0.014 & 0.010 & 0.012 & 0.010 & 0.010 \\
\hline
\end{tabular}

It can be observed that the $3^{\text {rd }} \mathrm{ROI}$ for mirror carp stands different than the rest. There is also not much difference between the color-based values and the grayscale-based values of the energies: the average energy values of $R, G$, and $B$ are within one standard deviation of the GS energy value. The minimum energy value in the table is 0.009 for scaled carp, ROI 3, R-based histogram.
The maximum value is 0.033 for mirror carp, $\mathrm{ROI} 4, \mathrm{~B}$ histogram. Most publications first convert a color image to grayscale (and cause loss of information), but deal with one value (grayscale) instead of 3 (R, G, B) (Basset et al.2000; Perez-Nieto et al., 2010). Based on this, the smallest grayscale value for energy is 0.009 , for scaled carp, ROI 3 . This means that the $3^{\text {rd }} \mathrm{ROI}$ has the most textured surface. 
The largest energy value for grayscale in Table 2 is 0.013 for mirror carp, ROI 4. This ROI is the "smoothest" based on this calculation.

Table 3 shows the histogram-based entropies of R, G, B and GS histograms. Again, the values are different for the $R$, $G, B$ and GS. The entropy values are in the order of 10 , they are bigger than the energy values, and can possibly perform better in the fine separation of visual texture. The largest GS entropy value is 6.854 for scaled carp, ROI 3 . This is the same ROI that has the lowest energy. Also, the smallest GS entropy value is 6.376 for mirror carp, ROI 4 . This is the same $\mathrm{ROI}$ that has the largest energy. Therefore, it is confirmed that energy and entropy work in reverse of each other.

Table 3. Histogram based entropies of carp image objects

\begin{tabular}{lllllllll}
\hline & \multicolumn{7}{l}{ Mirror carp } & \multicolumn{5}{c}{ Scaled Carp } \\
\cline { 2 - 8 } Object & $\mathbf{1}$ & $\mathbf{2}$ & $\mathbf{3}$ & $\mathbf{4}$ & $\mathbf{1}$ & $\mathbf{2}$ & $\mathbf{3}$ \\
\hline R entropy & 6.721 & 6.587 & 6.951 & 6.692 & 6.810 & 6.601 & 6.948 \\
G entropy & 6.695 & 6.451 & 6.905 & 6.426 & 6.783 & 6.568 & 6.892 \\
B entropy & 6.453 & 5.367 & 6.002 & 5.254 & 6.543 & 6.280 & 6.514 & 6.825 \\
GS entropy & 6.678 & 6.382 & 6.830 & 6.376 & 6.753 & 6.532 & 6.854 \\
\hline
\end{tabular}

Table 4 displays the results of co-occurrence matrixbased calculation of energy values (Equation 4 ) for 0 degrees and step size $=1$. Notice that the energy values of scaled carp (more visual texture) are almost an order of magnitude smaller than those of the mirror carp (less visual texture). Therefore, in this method of calculation, the separation of visual texture is better. The maximum GS energy value in
Table 4 is 2.782 for mirror carp, ROI 3 , as in the case of histogram-based energy calculations (Table 2). Also, the minimum energy value for GS is 0.226 for scaled carp, ROI 1 . This is different than the case of Table 2 (ROI 3). Looking at Figure 1, it can be argued that scaled carp ROI 1 has the most visual texture, but this assertion is not based on sensory evaluation.

Table 4. Co-occurrence matrix-based energies of carp image objects

\begin{tabular}{lllllllll}
\hline & \multicolumn{7}{c}{ Mirror carp } & \multicolumn{7}{c}{ Scaled Carp } \\
\cline { 2 - 9 } Object & $\mathbf{1}$ & $\mathbf{2}$ & $\mathbf{3}$ & $\mathbf{4}$ & $\mathbf{1}$ & $\mathbf{2}$ & $\mathbf{3}$ & $\mathbf{4}$ \\
\hline R energy & 0.704 & 0.881 & 2.611 & 1.001 & 0.218 & 0.257 & 0.499 & 0.275 \\
G energy & 0.726 & 1.008 & 2.538 & 1.246 & 0.227 & 0.261 & 0.516 & 0.277 \\
B energy & 0.759 & 2.270 & 3.877 & 2.949 & 0.269 & 0.323 & 0.664 & 0.328 \\
GS energy & 0.734 & 1.067 & 2.782 & 1.272 & 0.226 & 0.264 & 0.533 & 0.283 \\
\hline
\end{tabular}

Table 5 presents the results of co-occurrence matrixbased calculation of entropy values (Equation 5) for 0 degrees, step size $=1$. The magnitudes of the entropy values compared to Table 3 are much larger, in the range of $10^{2}$, which may be advantageous if fine separation of the visual texture is required. The largest grayscale entropy is 221.897 for scaled carp, ROI 3, as before. The smallest entropy is 99.887 for mirror carp, ROI 2. This is different than Table 3 where the minimum entropy was for mirror carp, ROI 4 . This emphasizes the possibility of different results of evaluating visual texture based on different methods of entropy calculation.

Table 5. Co-occurrence matrix-based entropies of carp image objects

\begin{tabular}{lllllllll}
\hline & Mirror carp & \multicolumn{7}{c}{ Scaled Carp } \\
\cline { 2 - 10 } Object & $\mathbf{1}$ & $\mathbf{2}$ & $\mathbf{3}$ & $\mathbf{4}$ & $\mathbf{1}$ & $\mathbf{2}$ & $\mathbf{3}$ & $\mathbf{4}$ \\
\hline R entropy & 105.201 & 103.687 & 162.404 & 125.166 & 131.720 & 133.344 & 224.804 & 163.436 \\
G entropy & 104.508 & 101.095 & 161.833 & 119.467 & 130.994 & 133.220 & 223.407 & 163.178 \\
B entropy & 102.489 & 82.928 & 136.63 & 93.886 & 127.342 & 127.907 & 211.441 & 158.238 \\
GS entropy & 104.078 & 99.887 & 158.651 & 118.272 & 130.981 & 132.614 & 221.897 & 162.346 \\
\hline
\end{tabular}


Table 6 shows the average slopes for R, G, B, and GS based fractal calculations. The average $R^{2}$ values are high (above 0.99). Again, concentrating on the GS values, for mirror carp the GS slope averages are all close to 1.6 for the four ROls. The standard deviations are in the range of 0.1 . This shows that all the GS slope averages are within 1 standard deviation of each other.

Therefore, there is no statistical difference between the grayscale slopes for any ROI. The same is true for the scaled carp GS slope averages: they are all close to 1.65. The standard deviations are all in the range 0.11. Again, the average GS slopes are within one standard deviation from each other. Furthermore, the GS average slopes of mirror carp and scaled carp are within one standard deviation of each other. Therefore, although there is significant visual texture difference between the mirror carp and the scaled carp, the fractals method used here cannot differentiate this difference in visual texture.

Table 6. Fractal dimensions of carp image objects

\begin{tabular}{|c|c|c|c|c|c|c|c|c|}
\hline \multirow[t]{2}{*}{ Object } & \multicolumn{4}{|c|}{ Mirror carp } & \multicolumn{4}{|c|}{ Scaled carp } \\
\hline & 1 & 2 & 3 & 4 & 1 & 2 & 3 & 4 \\
\hline R slope, avg & 1.651 & 1.654 & 1.690 & 1.672 & 1.654 & 1.654 & 1.689 & 1.669 \\
\hline St dev & 0.124 & 0.119 & 0.118 & 0.101 & 0.137 & 0.124 & 0.124 & 0.115 \\
\hline $\mathrm{R}^{2}$ avg & 0.998 & 0.998 & 0.998 & 0.998 & 0.997 & 0.997 & 0.997 & 0.997 \\
\hline G slope, avg & 1.651 & 1.655 & 1.691 & 1.673 & 1.656 & 1.654 & 1.690 & 1.670 \\
\hline St dev & 0.127 & 0.120 & 0.123 & 0.098 & 0.144 & 0.127 & 0.128 & 0.117 \\
\hline $\mathrm{R}^{2}$ avg & 0.998 & 0.998 & 0.998 & 0.998 & 0.997 & 0.997 & 0.997 & 0.997 \\
\hline B slope, avg & 1.655 & 1.654 & 1.691 & 1.669 & 1.660 & 1.657 & 1.691 & 1.673 \\
\hline St dev & 0.143 & 0.132 & 0.141 & 0.135 & 0.161 & 0.131 & 0.136 & 0.116 \\
\hline $\mathrm{R}^{2}$ avg & 0.997 & 0.997 & 0.997 & 0.997 & 0.996 & 0.997 & 0.997 & 0.997 \\
\hline GS slope, avg & 1.651 & 1.654 & 1.691 & 1.672 & 1.655 & 1.654 & 1.690 & 1.670 \\
\hline St dev & 0.126 & 0.119 & 0.121 & 0.099 & 0.142 & 0.126 & 0.127 & 0.116 \\
\hline $\mathrm{R}^{2}$ avg & 0.998 & 0.998 & 0.998 & 0.998 & 0.997 & 0.997 & 0.997 & 0.997 \\
\hline
\end{tabular}

Table 7 presents both the color and grayscale-based $\mathrm{TCl}$ values of mirror carp and scaled carp ROls calculated based on the texture primitives with an intensity threshold of 5 . The smallest $\mathrm{TCl}$ values (the smoothest visual texture) are that of mirror carp, $\mathrm{ROI} 3$. The largest $\mathrm{TCl}$ values are that of scaled carp, ROI 4. Also, there is enough range between the minimum (11) and maximum (101) values for fine separation between visual textures.
Another tool of the texture primitives method is the texture circles, shown in Figures 7 and 8. In the case of mirror carp (Figure 7), the visual texture is relatively smooth. This results in large circles, but few in number. However, in the case of scaled carp (Figure 8), with much visual texture, the circles are small and there are many of them. This gives another indication of the relative visual texture between samples.

Table 7. Texture Change Index values of carp image objects

\begin{tabular}{llllllll}
\hline Object & \multicolumn{1}{l}{ Mirror carp } & \multicolumn{5}{c}{ Scaled carp } \\
\cline { 2 - 7 } & $\mathbf{1}$ & $\mathbf{2}$ & $\mathbf{3}$ & $\mathbf{4}$ & $\mathbf{1}$ & $\mathbf{2}$ & $\mathbf{3}$ \\
\hline Color TCl & 24.371 & 19.834 & 12.478 & 20.173 & 105.452 & 80.939 & 95.657 \\
GS TCl & 23.107 & 15.318 & 11.077 & 12.511 & 96.477 & 73.261 & 78.649 \\
\hline
\end{tabular}




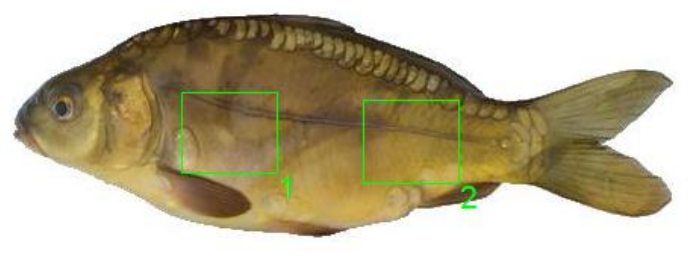

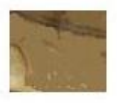

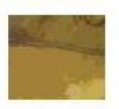

\section{Texture primitives}

\section{Texture circles}
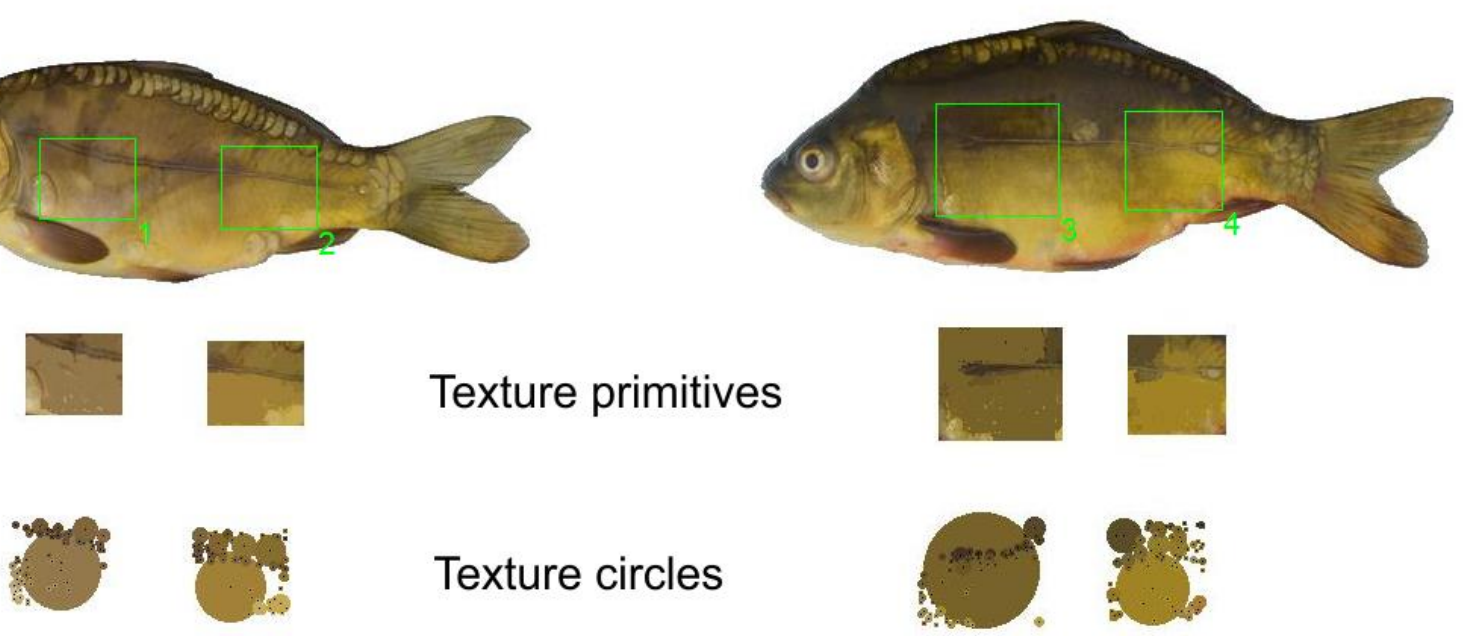

Figure 7. Texture primitives and texture circles for mirror carp
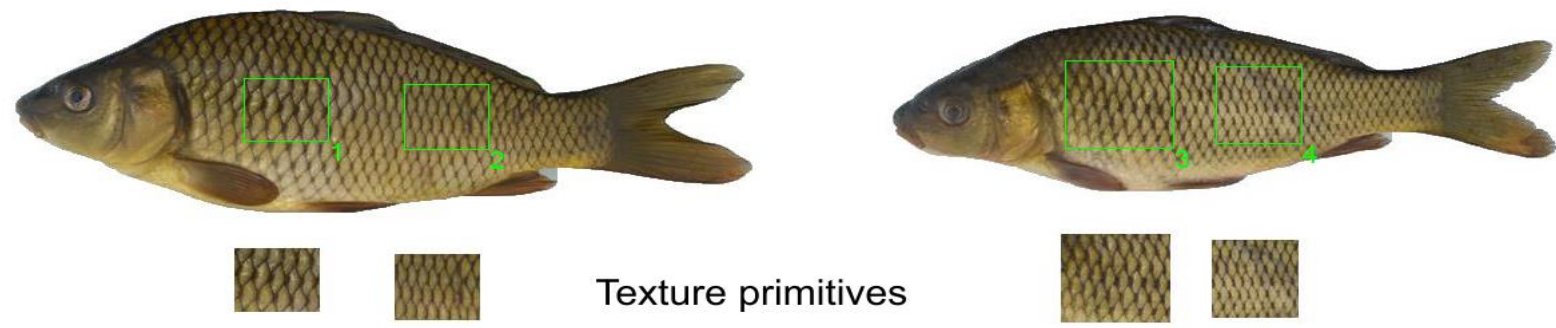

Texture primitives

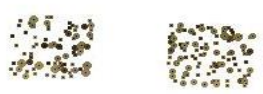

Texture circles
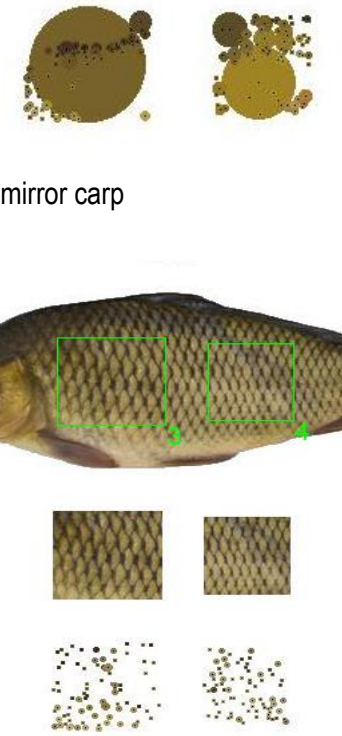

Figure 8. Texture primitives and texture circles for scaled carp

\section{CONCLUSION}

Table 8 summarizes the findings of this study. It is apparent that different image analysis-based methods to calculate visual texture may result in different conclusions. In Table 8 the minimum and maximum energy and entropy values differ depending on which method is used. Also, the identification of the smoothest and most textured images is different for different methods. An obvious solution to the selection of method is to correlate the results with that of a sensory study. However, sensory studies that correlate machine calculations to sensory panel results are difficult to find in the literature. This is mainly due to the difficulties in finding existing and established methods to quantify sensory panel evaluations of visual texture.

Another important criterion in the selection of method is the range between the minimum and maximum values. If the range is small, e.g., histogram-based energy, then the fine resolution of images with similar visual texture will be difficult.

Table 8. Summary of minimum and maximum values of parameters for different methods

\begin{tabular}{llllll}
\hline Object & Min value & Max value & Min ROI & Max ROI & Range \\
\hline Histogram energy & 0.009 & 0.013 & Scaled 3 & Mirror 4 & 0.004 \\
Histogram entropy & 6.375 & 6.854 & Mirror 4 & Scaled 3 & 0.478 \\
Co-occurrence energy & 0.226 & 2.781 & Scaled 1 & Mirror 3 & 2.555 \\
Co-occurrence entropy & 99.887 & 221.897 & Mirror 2 & Scaled 3 & 122.011 \\
Texture Change Index & 11.077 & 101.128 & Mirror 3 & Scaled 4 & 90.051 \\
\hline
\end{tabular}


This study suggests that the co-occurrence matrix-based analysis of entropy resulted in the largest range for our samples. The $\mathrm{TCl}$ method was a close second. However, the identification of the smoothest and roughest samples in these two methods is different. Therefore, it is clear that the correlation and merging of quantitative visual information, especially for foods, with sensory analysis must be done to bring meaning to the computer-based parameters.

\section{REFERENCES}

Alçiçek, Z. \& Balaban, M.O. (2012). Development and application of "The Two Image" method for accurate object recognition and color analysis. Journal of Food Engineering, 111(1), 46-51. DOI:10.1016/j.jfoodeng.2012.01.031

Balaban, M. O. (2008). Quantifying non-homogeneous colors in agricultural materials. Part I: Method development. Journal of Food Sciences, 73(9), 431-437. DOI: 10.1111/j.1750-3841.2008.00807.x

Balaban, M.O., Stewart, K., Fletcher, G.C. \& Alçiçek, Z. (2014). Color change of the snapper (Pagrus auratus) and gurnard (Chelidonichthys kumu) skin and eyes during storage: effect of light polarization and contact with ice. Journal of Food Sciences, 79(12), E2456-2479. DOI: $10.1111 / 1750-3841.12693$

Basset, O., Buquet, B., Abuelkaram, S., Delachartre, P. \& Culioli, J. (2000). Application of texture image analysis for the classification of bovine meat. Food Chemistry, 69, 437-445.

Bharati, M.H., Liu, J.J. \& MacGregor, J.F. (2004). Image texture analysis: methods and comparisons. Chemometrics and Intelligent Laboratory Systems, 72 (1), 57-71. DOI: 10.1016/j.chemolab.2004.02.005

Gümüş, E., Yılayaz, A., Kanyılmaz, M., Gümüş, B. \& Balaban., M. (2021). Evaluation of body weight and color of cultured European catfish (Silurus glanis) and African catfish (Clarias gariepinus) using image analysis. Aquacultural Engineering, 93, 102147. DOI:10.1016/j.aquaeng.2021.102147

Hendrawan, Y., Fauzi, M.R., Khoirunnisa, N.S., Andreane, M., Hartianti, P.O., Halim, T.D. \& Umam, C. (2019). Development of colour co-occurrence matrix (CCM) texture analysis for biosensing, IOP Conference Series: Earth and Environmental Science, 230, 012022. DOI:10.1088/1755-1315/230/1/012022

Larkin, K.G. (2016). Reflections on Shannon information: In search of a natural information-entropy for images. [Online]. Available: https://arxiv.org/abs/1609.01117 (01.05.2021).

Luzuriaga, D.A., Balaban, M.O. \& Yeralan, S. (1997). Analysis of visual quality attributes of white shrimp by machine vision. Journal of Food Sciences, 62(1), 113-119. DOI: 10.1111/j.1365-2621.1997.tb04379.x

Oliveira, A. C. M., Crapo, C. \& Balaban, M. O. (2006). Grading of pink salmon skin watermarking using a machine vision system. Second Joint Transatlantic Fisheries Technology Conference. October 29-November 1, 2006, Quebec City, Quebec, Canada. P-46, p. 138.

\section{ACKNOWLEDGEMENT}

The author would like to thank Prof. Dr. Murat O. Balaban for his invaluable technical support and Mr. Serkan ERKAN, Director of Republic of Turkey Ministry of Agriculture and Forestry, Mediterranean Fisheries Research Production and Training Institute, Antalya, Turkey.

Padmavathi, K. \& Thangadurai, K. (2016). Implementation of RGB and Grayscale images in plant leaves disease detection- comparative study. Indian Journal of Science and Technology. 9(6), 1-6. DOI: 10.17485/ijst/2016/v9i6/77739

Partio, M., Cramariuc, B., Gabbouj, M. \& Visa, A. (2002). Rock Texture Retrieval Using Gray Level Co-Occurrence Matrix. 5th Nordic Signal Processing Symposium, Oct. 2002.

Pathak, B. \& Barooah, D. (2013). Texture analysis based on the gray level co-occurrence matrix considering possible orientations. International Journal of Advanced Research in Electrical, Electronics and Instrumentation Energy, 2(9), 4206-4212.

Perez-Nieto, A., Chanona-Perez, J.J., Farrera-Rebollo, R.R., GutierrezLopez, G.F., Alamilla-Beltran, L. \& Calderon-Dominguez, G. (2010). Image analysis of structural changes in dough during baking. LWTFood Science and Technology, 43, 535-543.

Sharma, M., Markou, M. \& Singh, S. (2001). Evaluation of texture methods for image analysis. in Intelligent Information Systems Conference, The Seventh Australian and New Zealand IEEE, 117-121.

Tamura, H., Mori, S. \& Yamawaki, T. (1978). Textural features corresponding to visual perception. IEEE Transactions on Systems, Man and Cybernetics, SMC-8 (6), 460-473.

Tuceryan, M. (1998). Texture analysis. In" The handbook of Pattern Recognition and Computer Vision, $2^{\text {nd }}$ edition", Chen $\mathrm{C} \mathrm{H}$, Pau L F, Wang P S P, editors. Chapter 2.1 p: 207-248. World Scientific Publishing Co.

Varma, M. \& Garg, R. (2007). Locally invariant fractal features for statistical texture classification. IEEE $11^{\text {th }}$ International Conference on Computer Vision. 1-8. IEEEXPLORE.IEEE.ORG.

Zheng, C., Sun, D.W. \& Zheng L. (2006). Recent developments and applications of image features for food quality evaluation and inspection - a review. Trends in Food Science Technology, 17, 642-655. DOI: 10.1016/j.tifs.2006.06.005

Zheng, C., Sun, D.W. \& Zheng, L. (2007). A new region-primitive method for classification of colour meat image texture based on size, orientation, and contrast. Meat Science, 76, 620-627. DOI: 10.1016/j.meatsci.2007.02.003

Zucker, S.W. \& Terzopoulos, D. (1980). Finding structure in co-occurrence matrices for texture analysis. Computer Graphics and Image Processing, 12, 286-308. DOI: 10.1016/0146-664X(80)90016-7 